\title{
Hormone replacement therapy: characteristics of users and non-users in a British general practice cohort identified through computerised prescribing records
}

Tim Lancaster, Geraldine Surman, Martin Lawrence, David Mant, Martin Vessey, Margaret Thorogood, Patricia Yudkin, Edel Daly

\begin{abstract}
Study objective - To assess the feasibility of recruiting a cohort of women, including long term users of postmenopausal hormone replacement therapy (HRT), through computerised general practice prescribing records, and to compare clinical and demographic characteristics of users and non-user controls.
\end{abstract}

Design - Cross sectional analysis of questionnaire data.

Setting - Subjects were recruited through 17 general practices in the Oxfordshire, south west Thames, and north west Thames regions that contributed to the VAMP Research Database.

Participants - A total of 2964 women aged 45-64 years were identified. Altogether 1482 were long term ( $>1$ year) users of HRT and 1482 were non-user controls: 1037 $(70 \%)$ of the users and $819(55 \cdot 3 \%)$ of the controls agreed to participate and provided questionnaire data.

Imperial Cancer Research Fund General Practice Research Group, Radcliffe Infirmary, Oxford OX2 6HE

$T$ Lancaster

G Surman

$P$ Yudkin

University

Department of Public

Health and Primary

Care, Radcliffe

Infirmary, Oxford

$M$ Vessey

$M$ Lawrence

E Daly

University of

Southampton,

Department of

Primary Medical

Care, Aldermoor

Health Centre,

Southampton

D Mant

Health Promotion

Sciences Unit,

Department of Public

Health and Policy,

London School of

London School of
Hygiene and Tropical

Medicine, London

$M$ Thorogood

Correspondence to: Dr T Lancaster.

Accepted for publication March 1995
Main results - Users of HRT were more likely to have undergone hysterectomy than controls. Most women with a history of hysterectomy used unopposed oestrogen, while those with intact uteri generally used a combination of oestrogen and a progestagen. Among women who had undergone hysterectomy, HRT users did not differ significantly from controls over a range of demographic and clinical characteristics but they were more likely to be past users of oral contraceptives. Among women with intact uteri, users were similar to controls in terms of reported clinical characteristics, but were of higher social class and were more likely to be past users of oral contraceptives and to have had a mammogram after the age of 50 . Compared with the general population, all catwere of higher social class and exhibited more health conscious behaviours.

Conclusions - Electronic general practice prescribing records provide a feasible and efficient method for recruiting women to a cohort of HRT. Women who agreed to participate in this study were not representative of the general population, emphasising the importance of internal controls in such a study. Among participants, HRT users who had not unegories of women recruited to the study dergone hysterectomy showed evidence of better health than non-users on some dimensions. In the whole sample, however, there were no appreciable differences in social class and self reported health indicators between users and controls.

\section{( $(\mathcal{F}$ Epidemiol Community Health 1995;49:389-394)}

The ratio of benefit to risk for long term use of hormone replacement therapy (HRT) in postmenopausal women is a question of great public interest. Estimates from observational studies $^{12}$ suggest that sustained use of HRT could reduce the incidence of myocardial infarction by up to $50 \%$, and substantially reduce morbidity and mortality from fractures associated with osteoporosis. These benefits have to be weighed against possible increases in the risk of breast cancer and endometrial cancer. Daly $e t a l^{\beta}$ have considered these issues in detail and have shown that, on the basis of present knowledge, it is likely that benefits outweigh risks.

Three main concerns have, however, checked enthusiasm for increased use of HRT as a method of disease prevention. The first is that data on benefits and risks come exclusively from observational studies, and selection of healthier women to receive treatment may exaggerate the apparent benefits of HRT. The second concern is that those studies which have reported favourably on the effects of HRT have largely considered the use of unopposed oestrogen. In current clinical practice women who have not undergone hysterectomy usually receive oestrogens combined with some form of progestagen, to protect against endometrial cancer. Recent data suggest that these combinations may exert beneficial effects on some cardiovascular risk factors, ${ }^{4}$ but there remains concern that progestagens will reduce the protective effects of unopposed oestrogens, especially on serum lipids. ${ }^{5}$ Differences in type of hormone, dose, and duration of treatment, and in the use of cyclic or continuous combination regimens also confound the issue. The third concern is that it is largely unknown whether the benefits and risks of HRT are confined to current or recent users, or whether they are also apparent in past users.

These uncertainties have led to calls for large scale randomised trials of HRT. ${ }^{56}$ Through 
their control of selection bias, well conducted randomised controlled trials provide the best evidence for or against particular treatments, especially pharmacological, interventions. ${ }^{7}$ The main barriers to performing a successful randomised controlled trial of HRT are feasibility and cost. ${ }^{5}$ A large sample size and extended follow up are required to determine the incidence of outcomes of different prevalence and varying latency. Any randomised comparison will therefore be expensive, and will face difficulties in preventing contamination of the allocated treatment groups. Women with menopausal symptoms may not consent to or maintain randomisation to placebo. Likewise, asymptomatic women may lack the motivation to sustain long term use. Significant crossover between groups could negate the advantages of randomisation as a method of controlling bias.

If attempts to mount a randomised controlled trial are unsuccessful, other methodologies will be needed to address the outstanding questions. Although there have been a number of large cohort studies of the effects of unopposed oestrogen, there are few observational data on combined therapy. A British cohort study, in which $43 \%$ of subjects were using combined therapy, found lower overall mortality and a lower risk of death from cardiovascular disease than expected on the basis of national rates. ${ }^{89}$ However, this study lacked power to detect rarer outcomes. In particular, the suggestion of an increased risk of mortality from breast cancer with increasing duration since first use of HRT could not be confirmed because of insufficient numbers. The study was also limited by a lack of internal controls, a particular problem because of probable selection bias in the method of recruitment through specialised menopause clinics. A British case-control study ${ }^{10}$ found increased risks of myocardial infarction and stroke in women taking unopposed oestrogen and near baseline risk in those taking combined therapy. A recent Scandinavian cohort study of 23000 women prescribed HRT, using record linkage between prescription and hospital admission data, ${ }^{11}$ reported a $50 \%$ reduced risk of myocardial infarction for those using combined therapy, but found evidence of significant selection bias when a sample of cohort women were compared with a sample of non-users drawn from the general population. This study also lacked internal controls: rates in users were compared with expected rates based on incidence rates of myocardial infarction in the whole population of the Uppsala region, so that direct adjustment for confounders could not be made in the analyses.

As an alternative to a randomised trial, a cohort study of HRT should be large enough to address rare outcomes with adequate power in women taking oestrogen/progestagen combinations, utilise internal controls to allow accurate adjustment for confounding, and be feasible at lower cost. The increasing use of desk top computers for prescribing and recording medical data in general practice offers a potential method for identifying and following such a cohort. To test the feasibility of this method, we undertook a pilot study using the VAMP Research Database. The aims of the study were as follows:

- To identify long term users of HRT and controls in general practice;

- To determine the willingness of women identified to provide personal medical data and consent to follow up;

- To validate computer derived data against information provided by patients; and

- To delineate the characteristics and comparability of users and non-users.

We report here on the success of recruitment and describe the clinical and demographic characteristics of these two groups.

\section{Methods}

Between July 1989 and June 1990 about 1000 general practitioners agreed, in exchange for reimbursement for computer costs, to provide VAMP Health (a commercial company) with standardised, anonymised information from medical records for research purposes. The information to be recorded included demographic details, all medical diagnoses and referrals to hospital, and a record of all prescriptions issued. After a period of training, the quality of recorded data was assessed by standardised validation procedures. Practices which met these criteria, and continued to maintain the quality of their data, were eligible to provide data for research. Previous validation studies have suggested that the clinical information recorded on the computer is suitable for many clinical studies. ${ }^{12}$

In 1993, the prevalence of current and long term ( $>1$ year) use of HRT in women aged 45-64 years was determined by reviewing the anonymised prescribing records of all women in this age group registered with 28 general practices in the south west Thames and Oxford health regions who contributed to the VAMP database. Practices from these regions were then approached individually to determine their willingness to allow direct approaches to their patients and recruitment was stopped after 17 practices had agreed to participate (six in the Oxford region, five in north west Thames, and six in south west Thames). All the practices who were approached had satisfied VAMP criteria for quality of data collection. Local ethics committees approved the study protocol in each district where practices participated.

Women aged 45-64 years who had been prescribed any of 13 HRT preparations in the 6 months before the last data collection date and women aged 45-64 who had been prescribed any HRT in the 12-18 months before the last data collection date were identified from the practice records kept on the database. Women common to both groups were classified as long term users, and the next woman of the same age on the register who had not received any prescription for HRT in the preceding five years was selected as a control. Each woman identified in this way was sent a letter of invitation and a questionnaire to fill in if she consented to enter the study. This ques- 
Table 1 Relationship between long term hormone replacement therapy (HRT) use, hysterectomy, and ovarian status

\begin{tabular}{lcclll}
\hline & \multicolumn{2}{l}{ Non-users of $H R T$} & & \multicolumn{2}{l}{ Users of $H R T$} \\
\cline { 2 - 3 } \cline { 5 - 6 } & $\begin{array}{l}\text { No of } \\
\text { women }\end{array}$ & $(\%)$ & & $\begin{array}{l}\text { No of } \\
\text { women }\end{array}$ & $(\%)$ \\
\hline Women with & 68 & $(85)$ & & 608 & $(59)$ \\
intact uteri & 686 & $(11)$ & & 261 & $(25)$ \\
H-BSO & 88 & $(3)$ & & 140 & $(14)$ \\
H+BSO & 21 & $(1)$ & & 21 & $(2)$ \\
H+OSU & 14 & $(14$ &
\end{tabular}

$\mathrm{H}=$ hysterectomy; $\quad \mathrm{BSO}=$ bilateral salpingo-oophorectomy; OSU = ovarian status unknown

tionnaire enquired about the history of HRT use, past experience of medical events that might have led to hospital admission, height and weight, menopausal status, smoking status, exercise habits, family history of cardiovascular disease, level of education, home ownership, occupation of subject and spouse, history of long term chronic illnesses, and consent to examine medical records. A subset of women was sent a longer questionnaire asking for additional information on alcohol intake, diet, history of fracture or osteoporosis, and questions about menopausal symptoms.

In this analysis, data from the questionnaires completed by consenting women were used to compare those using HRT with controls, with further analysis by hysterectomy status, to determine whether they differed in terms of characteristics known, or suspected, to confound the relationship between exposure and cardiovascular disease or cancer. Social class was

Table 2 Characteristics of users and non-users of hormone replacement therapy: women with a history of hysterectomy

\begin{tabular}{|c|c|c|c|c|}
\hline & \multicolumn{2}{|c|}{ Non-users $(n=123)$} & \multicolumn{2}{|c|}{ Users $(n=422)$} \\
\hline & No & $(\%)$ & No & (\%) \\
\hline \multicolumn{5}{|l|}{ Social class: } \\
\hline I & 12 & $(10 \cdot 2)$ & 40 & $(9 \cdot 8)$ \\
\hline II & 42 & $(35 \cdot 6)$ & 152 & $(37 \cdot 2)$ \\
\hline IIIN & 14 & $(11 \cdot 9)$ & 60 & $(14 \cdot 7)$ \\
\hline IIIM & 33 & $(28 \cdot 0)$ & 104 & $(25 \cdot 4)$ \\
\hline IV & 13 & $(11 \cdot 0)$ & 39 & $(9 \cdot 5)$ \\
\hline V & 4 & $(3.4)$ & 14 & $(3 \cdot 4)$ \\
\hline Home ownership & 107 & $(87 \cdot 0)$ & 370 & $(90 \cdot 0)$ \\
\hline \multicolumn{5}{|l|}{ Age at end of full time education (y): } \\
\hline$\leq 15$ & 64 & $(52 \cdot 5)$ & 203 & $(48 \cdot 8)$ \\
\hline $\overrightarrow{16-19}$ & 44 & $(36 \cdot 1)$ & 171 & $(41 \cdot 1)$ \\
\hline$>19$ & 14 & $(11 \cdot 5)$ & 42 & $(10 \cdot 1)$ \\
\hline Married & 98 & $(79 \cdot 7)$ & 354 & $(84 \cdot 7)$ \\
\hline \multicolumn{5}{|l|}{ Smoking status: } \\
\hline Current & 27 & $(22 \cdot 1)$ & 63 & $(15 \cdot 1)$ \\
\hline Previous & 40 & $(32 \cdot 8)$ & 161 & $(38 \cdot 7)$ \\
\hline Never & 55 & $(45 \cdot 1)$ & 192 & $(46 \cdot 2)$ \\
\hline History of hypertension & 16 & $(13 \cdot 2)$ & 63 & $(15 \cdot 1)$ \\
\hline Family history of heart disease & 38 & $(30.9)$ & 171 & $(40 \cdot 5)$ \\
\hline Family history of breast cancer & 14 & $(11 \cdot 4)$ & 38 & $(9 \cdot 0)$ \\
\hline History of breast lumps & 32 & $(26 \cdot 0)$ & 103 & $(24 \cdot 4)$ \\
\hline \multicolumn{5}{|l|}{ Physical activity: } \\
\hline Sedentary & 23 & $(19 \cdot 3)$ & 116 & $(27 \cdot 8)$ \\
\hline Moderate & 81 & $(68 \cdot 1)$ & 270 & $(64 \cdot 7)$ \\
\hline Vigorous & 15 & $(12 \cdot 6)$ & 31 & $(7 \cdot 4)$ \\
\hline \multicolumn{5}{|l|}{ Body mass index*: } \\
\hline$<20$ & 9 & $(7 \cdot 8)$ & 25 & $(6 \cdot 1)$ \\
\hline $20-24$ & 48 & $(41 \cdot 7)$ & 198 & $(48 \cdot 4)$ \\
\hline $25-29$ & 46 & $(40 \cdot 0)$ & 133 & $(32 \cdot 5)$ \\
\hline$>30$ & 12 & $(10 \cdot 4)$ & 53 & $(13 \cdot 0)$ \\
\hline \multicolumn{5}{|l|}{ Alcohol (U per wk)t: } \\
\hline 0 & 19 & $(25 \cdot 3)$ & 47 & $(16 \cdot 2)$ \\
\hline$<1$ & 28 & $(37 \cdot 3)$ & 100 & $(34 \cdot 5)$ \\
\hline $1-7$ & 14 & $(18 \cdot 7)$ & 101 & $(34 \cdot 8)$ \\
\hline $8-14$ & 10 & $(13 \cdot 3)$ & 26 & $(9 \cdot 0)$ \\
\hline$\geqslant 15$ & 4 & $(5 \cdot 3)$ & 16 & $(5 \cdot 5)$ \\
\hline Past oral contraceptive use & 63 & $(51 \cdot 6)$ & 268 & $(64 \cdot 0) \ddagger$ \\
\hline Women aged $>50$ having a mammogram & 95 & $(84 \cdot 1)$ & 290 & $(84 \cdot 1)$ \\
\hline Bilateral oophorectomy & 21 & $(17 \cdot 5)$ & 140 & $(33 \cdot 6) \S$ \\
\hline
\end{tabular}

* Weight $\mathrm{kg} /$ height $\left(\mathrm{m}^{2}\right) ; \dagger \mathrm{n}=$ non-users 75 , users $290 ; \ddagger \mathrm{p}<0.01, \emptyset \mathrm{p}<0.005$, all other $\mathrm{p}$ value $>0.05$. Percentages are based on numbers responding to each question. classified according to occupational status of partners, or by the woman's own occupation if she had no partner. Proportions were compared with the $\chi^{2}$ test, and means with $t$ tests. Ordered categories were compared with the $\chi^{2}$ test of trend. Confidence intervals were calculated using the Confidence Interval Analysis programme. ${ }^{13}$ Minor inconsistencies in the tables reflect rounding or missing values for some variables.

\section{Results}

The prevalence of current HRT use was $14 \cdot 7 \%$ and that of long term use was $10 \cdot 1 \%$ in women aged 45-64. Altogether, 2964 potential subjects were identified in the 17 participating practices - 1482 long term users of HRT and 1482 nonuser controls. Totals of $1037(70 \%)$ of the users and $819(55.3 \%)$ of the controls completed the questionnaires. Table 1 shows the relationship between hysterectomy status, presence or absence of the ovaries, and use of HRT. Information on hysterectomy status was missing for 17 women who entered the study. Of the remainder, $422(41 \%)$ of the users had a history of hysterectomy compared with $123(15 \cdot 2 \%)$ of controls (difference $25.8 \%, 95 \%$ confidence interval (CI) $21 \cdot 9,29 \cdot 7 \%, \mathrm{p}<0.001$ ). One hundred and forty $(13.5 \%)$ of the users had a history of bilateral oophorectomy compared with $21(2.6 \%)$ of the controls (difference $11 \%$, $95 \%$ CI 8.6, 13.4\%, $\mathrm{p}<0.001$ ). Among current users of HRT, $95.5 \%$ of women who had undergone hysterectomy were using unopposed oestrogen preparations and $96.3 \%$ of women with intact uteri were using some form of oestrogen/progestagen combination. Since the presence or absence of the uterus is such an important determinant in the prescribing decision, further comparisons between users and controls were made according to hysterectomy status.

\section{WOMEN WITH A HISTORY OF HYSTERECTOMY} In women who had undergone hysterectomy, the mean (SD) age of users was 54.41 (4.82) years and that of controls was $55 \cdot 7(4 \cdot 87)$ years. Reported demographic and clinical characteristics of the two groups are shown in table 2. There was no significant difference in social class distribution between the two groups in relation to occupation, housing status, or age of leaving full time education. There were no significant differences in marital status, smoking status, body mass index, exercise habits, personal history of hypertension, or in alcohol use in the subset of patients who reported on this. Family history of breast cancer and heart disease were comparable in the two groups. Users were more likely than controls to have undergone bilateral oophorectomy (difference $16 \cdot 1 \%, 95 \%$ CI $8 \cdot 0,24 \cdot 1 \%, \mathrm{p}<0.002)$. They were more likely than controls to have a past history of oral contraceptive use (difference $12.3 \%, 95 \%$ CI $2 \cdot 3,22 \cdot 2 \%, p<0 \cdot 01$ ), but no more likely to have had a mammogram after the age of 50 . 
Table 3 Characteristics of users and non-users of hormone replacement therapy: women with no history of hysterectomy

\begin{tabular}{|c|c|c|c|c|}
\hline & \multicolumn{2}{|c|}{ Non-users $(n=686)$} & \multicolumn{2}{|c|}{ Users $(n=608)$} \\
\hline & No & $(\%)$ & No & $(\%)$ \\
\hline \multicolumn{5}{|l|}{ Social class: } \\
\hline I & 82 & $(12 \cdot 3)$ & 80 & $(13 \cdot 6)$ \\
\hline II & 245 & $(36 \cdot 7)$ & 236 & $(40 \cdot 1)$ \\
\hline IIIN & 105 & $(15 \cdot 7)$ & 77 & $(13 \cdot 1)$ \\
\hline IIIM & 133 & $(19 \cdot 9)$ & 146 & $(24 \cdot 8)$ \\
\hline IV & 73 & $(10.9)$ & 35 & $(6 \cdot 0)$ \\
\hline $\mathrm{V}$ & 29 & $(4 \cdot 3)$ & 14 & $(2 \cdot 4)^{*}$ \\
\hline Home ownership & 588 & $(86 \cdot 6)$ & 554 & $(92 \cdot 0) \dagger$ \\
\hline \multicolumn{5}{|l|}{ Age at end of full time education (y): } \\
\hline$\leq 15$ & 285 & $(41 \cdot 9)$ & 241 & $(40 \cdot 0)$ \\
\hline$\overline{16}-19$ & 289 & $(42 \cdot 4)$ & 270 & $(44 \cdot 8)$ \\
\hline$>19$ & 107 & $(15 \cdot 7)$ & 92 & $(15 \cdot 3)$ \\
\hline Married & 549 & $(80 \cdot 5)$ & 498 & $(82 \cdot 3)$ \\
\hline \multicolumn{5}{|l|}{ Smoking status: } \\
\hline Current & 120 & $(17 \cdot 9)$ & 114 & $(19 \cdot 0)$ \\
\hline Previous & 196 & $(29 \cdot 2)$ & 200 & $(33 \cdot 3)$ \\
\hline Never & 355 & $(52 \cdot 9)$ & 287 & $(47 \cdot 8)$ \\
\hline History of hypertension & 71 & $(10 \cdot 4)$ & 59 & $(9 \cdot 8)$ \\
\hline Family history of heart disease & 248 & $(36 \cdot 2)$ & 203 & $(33 \cdot 4)$ \\
\hline Family history of breast cancer & 58 & $(8 \cdot 5)$ & 55 & $(9 \cdot 0)$ \\
\hline History of breast lumps & 139 & $(20 \cdot 3)$ & 148 & $(24 \cdot 3)$ \\
\hline \multicolumn{5}{|l|}{ Physical activity: } \\
\hline Sedentary & 173 & $(25 \cdot 4)$ & 166 & $(27 \cdot 4)$ \\
\hline Moderate & 460 & $(67 \cdot 6)$ & 380 & $(62 \cdot 7)$ \\
\hline Vigorous & 47 & $(6.9)$ & 60 & $(9 \cdot 9)$ \\
\hline \multicolumn{5}{|l|}{ Body mass index } \\
\hline$<20$ & 44 & $(6 \cdot 9)$ & 42 & $(7 \cdot 4)$ \\
\hline $20-24$ & 356 & $(55 \cdot 7)$ & 333 & $(58 \cdot 8)$ \\
\hline $25-29$ & 177 & $(27 \cdot 7)$ & 151 & $(26 \cdot 7)$ \\
\hline$>30$ & 62 & $(9 \cdot 7)$ & 40 & $(7 \cdot 1)$ \\
\hline \multicolumn{5}{|l|}{ Alcohol (U per wk)q: } \\
\hline 0 & 76 & $(16 \cdot 4)$ & 46 & $(11 \cdot 6)$ \\
\hline$<1$ & 159 & $(34 \cdot 3)$ & 125 & $(31 \cdot 5)$ \\
\hline $1-7$ & 165 & $(35 \cdot 6)$ & 152 & $(38 \cdot 3)$ \\
\hline $8-14$ & 43 & $(9 \cdot 3)$ & 46 & $(11 \cdot 6)$ \\
\hline $15 \&$ over & 20 & $(4 \cdot 3)$ & 28 & $(7 \cdot 1)$ \\
\hline Past oral contraceptive use & 369 & $(54 \cdot 3)$ & 374 & $(61 \cdot 7)$ \\
\hline Women aged $>50$ having a mammogram & 407 & $(75 \cdot 7)$ & 418 & $(83 \cdot 3) t$ \\
\hline Bilateral oophorectomy & 4 & $(0 \cdot 6)$ & 3 & $(0.5)$ \\
\hline
\end{tabular}

${ }^{*} \mathrm{p}<0.005,+\mathrm{p}<0.001, \ddagger \mathrm{p}<0.01$, all other $\mathrm{p}$ values $>0.05 ; §$ Weight $\mathrm{kg} /$ height $\left(\mathrm{m}^{2}\right) ; \uparrow \mathrm{n}=$ nonusers 463 (76 missing), users 397 (46 missing). Percentages are based on numbers responding to each question. and to be of a higher social class as measured by occupational status. Users were more likely to be past users of oral contraceptives (difference $7 \cdot 7 \%, 95 \%$ CI $2 \cdot 4,13 \cdot 1 \%, p<0 \cdot 01$ ) and those over 50 years of age were more likely to have had a mammogram than controls (difference $7.5 \%, 95 \%$ CI $2.6,12.4 \%, \mathrm{p}<0.005)$. Other health indicators did not differ significantly between the two groups.

COMPARISON TO THE GENERAL POPULATIONS Table 4 shows selected characteristics of participants, expressed as percentages, compared with contemporaneous data from the general United Kingdom population. ${ }^{14}$ Participants in the study, both users and controls, were of higher social class and in general exhibited more healthy behaviours than the general population.

\section{Discussion}

A survey of general practitioners conducted in 1989-90 estimated that about $9 \%$ of female patients aged $40-64$ were receiving HRT. ${ }^{15}$ Our study shows that the prevalence of postmenopausal HRT use remains low. In the absence of clear evidence about the ratio of benefit to risk, enthusiasm for this treatment among British general practitioners and their patients continues to be guarded. As expected most, but not all, women with a history of hysterectomy were taking unopposed oestrogen, and those with no history of hysterectomy were taking combined oestrogen/progestagen therapy, confirming estimates in previous surveys. ${ }^{15}$ This is an important point to consider in planning observational studies. Direct comparison of the effects of opposed and unopposed oestrogen in women with the same hysterectomy status, which has been proposed as a comparison within a randomised trial, ${ }^{15}$ is unlikely to be possible using observational data.

Table 4 Comparison of study sample users and non-users of hormone replacement therapy with women in the general population

\begin{tabular}{|c|c|c|c|c|c|c|}
\hline & \multicolumn{3}{|c|}{ Age 45-54 (\%) } & \multicolumn{3}{|c|}{ Age 55-64 (\%) } \\
\hline & $\begin{array}{l}\text { General } \\
\text { population* }\end{array}$ & $\begin{array}{l}\text { Non-users } \\
(n=454)\end{array}$ & $\begin{array}{l}\text { Users } \\
(n=549)\end{array}$ & $\begin{array}{l}\text { General } \\
\text { population* }\end{array}$ & $\begin{array}{l}\text { Non-users } \\
(n=350)\end{array}$ & $\begin{array}{l}\text { Users } \\
(n=471)\end{array}$ \\
\hline \multicolumn{7}{|l|}{ Social class: } \\
\hline I \& II & 40 & 52 & 49 & 33 & 45 & 52 \\
\hline IIIN & 11 & 13 & 13 & 15 & 18 & 14 \\
\hline IIIM & 29 & 24 & 26 & 28 & 19 & 25 \\
\hline IV \& V & 20 & 12 & 12 & 23 & 19 & 9 \\
\hline Married & 81 & 84 & 85 & 72 & 76 & 82 \\
\hline \multicolumn{7}{|l|}{ Smoking status: } \\
\hline Current & 36 & 19 & 22 & 26 & 18 & 13 \\
\hline Previous & 21 & 31 & 36 & 24 & 29 & 34 \\
\hline Never & 43 & 51 & 42 & 50 & 53 & 53 \\
\hline \multicolumn{7}{|l|}{ Physical activity: } \\
\hline Levels 0,1 (sedentary) & 30 & 30 & 31 & 38 & 18 & 24 \\
\hline Levels 2, 3 (moderate) & 59 & 64 & 59 & 56 & 73 & 69 \\
\hline Levels 4,5 (vigorous) & 10 & 6 & 10 & 6 & 10 & 8 \\
\hline \multicolumn{7}{|l|}{ Body mass index: } \\
\hline$<20$ & 3 & 8 & 8 & 4 & 6 & 6 \\
\hline $20-24$ & 43 & 55 & 56 & 34 & 51 & 53 \\
\hline $25-30$ & 31 & 28 & 26 & 38 & 31 & 32 \\
\hline$>30$ & 23 & 9 & 10 & 25 & 12 & 9 \\
\hline \multicolumn{7}{|l|}{ Alcohol (U per wk): } \\
\hline 0 & 9 & 14 & 12 & 12 & 20 & 13 \\
\hline$\leq 1$ & 23 & 34 & 30 & $\begin{array}{l}29 \\
35\end{array}$ & $\begin{array}{l}34 \\
33\end{array}$ & $\begin{array}{l}36 \\
38\end{array}$ \\
\hline $1-7$ & 40 & 34 & 36 & $\begin{array}{l}35 \\
15\end{array}$ & $\begin{array}{r}33 \\
9\end{array}$ & $\begin{array}{r}38 \\
9\end{array}$ \\
\hline $\begin{array}{l}8-14 \\
15 \& \text { over }\end{array}$ & 17 & 11 & 12 & $\begin{array}{r}15 \\
9\end{array}$ & 3 & 3 \\
\hline 15 \& over & 12 & 6 & 9 & 9 & & \\
\hline
\end{tabular}

* Source of data: The Health of the Nation, Health Survey for England $1992^{13}$ 
Our data do, however, show that it is possible to recruit a large, well matched sample of long term users and controls in the community using computerised general practice prescribing records. This method was very efficient: the entire sample was identified in less than a month. Because the data reported here are based on patient self report only, we are unable to comment on the comparability of measurements from physical examination or laboratory investigation. However, the distribution of self reported risk factors for cardiovascular disease and breast cancer, including smoking, body mass index, exercise levels, family history of cardiovascular disease, hypertension, and breast cancer were comparable in our sample of users and controls, whether or not they had previously undergone a hysterectomy. In contrast, both users and controls exhibited better health and social profiles than the general population, underlining the importance of internal controls for reducing confounding in observational studies of HRT.

Previous observational studies have yielded inconsistent evidence about the extent of bias in selection for HRT. For known cardiovascular risk factors, a number of studies have reported lower blood pressures, ${ }^{16-18}$ or better lipid profiles $^{1619}$ in users. The pattern has not, however, been consistent: within individual studies the two groups usually differed on only one or two known risk factors. Nor have the findings been consistent between studies. In the largest studies, there was little difference between users and controls in distributions of cardiovascular risk factors including blood pressure, lipids, smoking, family history, and previous history of vascular disease. ${ }^{19-22}$ Prevalence of smoking has been particularly difficult to interpret, with some studies ${ }^{23}$ reporting lower rates in users, while in others, users have been more likely to smoke, ${ }^{10111618}$ leading to the suggestion that smokers may be more likely to receive treatment for menopausal symptoms because of an antioestrogenic effect of smoking. ${ }^{24}$ A biological explanation has also been proposed for the more consistent tendency of users to be leaner than controls, ${ }^{1116-202225}$ possibly reflecting greater susceptibility to menopausal symptoms in lean women with lower levels of circulating oestrogens.

The documented similarity between our two groups in distribution of known risk factors for disease does not rule out a bias towards selection of women with more healthy characteristics, or behaviours that are less easy to measure. Social class is an important predictor of health outcome, independent of known risk factors for disease, ${ }^{2627}$ and a bias towards the treatment of women with higher educational attainment or occupational status has been found in a number of studies of HRT. ${ }^{11} 16172023$ A tendency for the use of HRT to be prescribed more equally across the social spectrum has been noted in some recent surveys, ${ }^{2528}$ and a diffusion of attitudes from better to less educated women has been proposed as an explanation. ${ }^{28}$ This trend is partly supported by our data, in which there were no significant differences between the two groups on a num- ber of measures of social class in the cohort as a whole. Social class does, however, seem to be a factor in more discretionary treatment decisions. On the basis of occupation and home ownership, among those who had not undergone hysterectomy, higher social class women were more likely to receive HRT, usually an oestrogen/progestagen combination. Users in both groups were significantly more likely to be previous users of oral contraceptives, an effect found in several other studies. ${ }^{2242529}$ This could indicate a bias towards healthier women, or might be, as previously suggested, ${ }^{24}$ a behavioural effect, with women who have previous experience of taking exogenous hormones being more willing to consider use of postmenopausal hormones. Users who had not undergone hysterectomy were also more likely than controls to have had a mammogram at age 50 . This difference was not seen in patients with a hysterectomy, and provides further evidence that women taking combined therapy may exhibit more health conscious behaviours than non-users. Increased contact with health professionals for monitoring of treatment may also be a factor in increasing uptake of preventive procedures in this group.

Comparisons between users and controls may have been affected by the different rates of response to questionnaires in the two groups. Part of this difference is likely to be due to a higher proportion of "ghosts" among controls (that is, patients who never received the questionnaire because they had moved or died). ${ }^{30}$ HRT users were unlikely to fall into this category because they were defined by their recent contact with the practice for dispensing of medication. The alternative explanation, that there is a correlation between interest in health and willingness to participate in research is also plausible. Such a bias could understate differences between users and non-users in the population, though paradoxically it may ensure greater validity of comparisons between users and controls within a cohort study.

A well conducted randomised trial has the greatest likelihood of eliminating known and, particularly, unknown confounding factors in allocation of treatment. It is unclear whether it will be possible to mount such a trial of HRT. Our study has shown the feasibility of a quick and inexpensive method of recruiting long term users of HRT and controls to an observational study through general practice. It is likely that the standard of data recording required by VAMP can only be met in better organised and funded practices, which in turn are less likely to serve deprived populations. This was reflected in a demographic profile of the sample as a whole which was not representative of the general population. Although raising issues of generalisability, this bias should not affect the validity of a cohort study, provided internal controls are included. Our study shows that computerised records can also be used effectively to recruit women who are non-users to act as controls. In a further analysis in this cohort, we plan to validate patient questionnaire responses against general practice 
electronic records, and assess the accuracy of these records for assessing data from physical examination and laboratory measurement, and for monitoring subsequent morbidity and mortality. This will determine whether computer derived records can be used reliably in the follow up, as well as the identification, of a cohort for studying the long term effects of postmenopausal HRT.

1 Stampfer MJ, Colditz GA. Estrogen replacement therapy and coronary disease: a quantitative assessment of the epidemiologic evidence. Prev Med 1991;20:47-63.

2 Grady D, Rubin SM, Petitti DB, et al. Hormone therapy to prevent disease and prolong life in post menopausa women. Ann Intern Med 1992;117(12):1016-37.

3 Daly E, Roche M, Barlow D, Gray A, McPherson K, Vessey M. HRT: Analysis of benefits, risks and costs. $\mathrm{Br}$ Med Bull 1992;48:368-400.

4 Nabulsi AA, Folsom AR, White A, et al. Association of hormone-replacement therapy with various cardiovascular risk factors in post menopausal women. $N$ Engl f Med 1993;328:1069-75.

5 Meade TW, Berra A. Hormone replacement therapy and cardiovascular disease. Br Med Bull 1992;48:276-308.

6 Goldman L, Tosteson ANA. Uncertainty about post menopausal estrogen. N Engl ₹ Med 1991;325:800-2.

7 Sackett DL, Haynes RB, Guyatt GH, Tugwell P. Clinical epidemiology: $A$ basic science for clinical medicine. 2 nd ed. Boston, MA: Little Brown \& Co Inc, 1991.

8 Hunt K, Vessey M, McPherson K, Coleman M. Long-term surveillance of mortality and cancer incidence in women receiving hormone replacement therapy. Br $\mathcal{f}$ Obstet Gynaecol 1987;94:620-35.

9 Hunt K, Vessey M, McPherson K. Mortality in a cohort of long-term users of hormone replacement therapy: an of long-term users of hormone replacement therapy: an
updated analysis. Br f Obstet Gynaecol 1990;94:620-35.

10 Thompson SG, Meade TW, Greenberg G. The use of hormonal replacement therapy and the risk of stroke and myocardial infarction in women. $\mathcal{F}$ Epidemiol Community Health 1989;43:173-8.

11 Falkeborn M, Persson I, Adami HO, et al. The risk of acute myocardial infarction after oestrogen and oestrogenprogestagen replacement. Br $\mathcal{f}$ Obstet Gynaecol 1992;99: $821-8$.

12 Jick $H$, Jick SS, Derby LE. Validation of information recorded on general practitioner based computerised data
resource in the United Kingdom. BMF 1991;302:766-8.

13 Gardner SB, Winter PD, Gardner MJ. Confidence interval analysis (CLA). London: BMJ Publishing Group, 1991.

14 Breeze E, Maidment A, Bennett N, Flatley J, Carey S. Health survey for England 1992. London: HMSO, 1994; $18-34$

15 Wilkes HC, Meade TW. Hormone replacement therapy in general practice: a survey of doctors in the MRC's genera practice research framework. BMF 1991;302:1317-20.

16 Criqui MH, Suarez L, Barrett-Connor E, McPhillips J, Wingard DL, Garland C. Post menopausal estrogen use and mortality. Results from a prospective study in a defined, homogeneous community. Am $¥$ Epidemiol 1988 ; 128:606-14.

17 Hammond $\mathrm{CB}$, Jelovsek FR, Lee KL, Creasman WT, Parker RT. Effects of long-term estrogen replacement therapy. Am. Effects of long-term estrogen rep

18 Wolf PH, Madans JH, Finucane FF, Higgins M, Kleinman JC. Reduction of cardiovascular disease-related mortality among post menopausal women who use hormones: evidence from a national cohort. Am $\mathcal{F}$ Obstet Gynecol 1991 164:489-94.

19 Wilson PW, Garrison RJ, Castelli WP. Post menopausa estrogen use, cigarette smoking, and cardiovascular morbidity in women over 50: The Framingham study. N Engl f Med 1985;313:1044-9.

20 Bush TL, Barrett-Connor E, Cowan LD, et al. Cardiovascular mortality and non contraceptive use of estrogen in women: results from the lipid research clinics program follow-up study. Circulation 1987;75:1102-9.

21 Henderson BE, Paganini-Hill A, Ross RK. Estrogen replacement therapy and protection from acute myocardial placement therapy and protection from acute myo.

22 Stampfer MJ, Colditz GA, Willett WC, et al. Post menopausal estrogen therapy and cardiovascular disease. Tenyear follow-up from the nurses' health study. $N$ Engl f Med 1991;325:756-62.

23 Derby CA, Hume AL, Barbour MM, McPhillips JB, Lasate TM, Carleton RA. Correlates of post menopausal estrogen use and trends through the $1980 \mathrm{~s}$ in two south-easter New England communities. Am F Epidemiol 1993;137: 1125-35.

24 Greenberg G, Thompson SG, Meade TW. Relation between cigarette smoking and use of hormonal replacement therapy for menopausal symptoms. 7 Epidemiol Community Health 1987;41:26-9.

25 Egeland GM, Kuller LH, Matthews KA, Kelsey SF, Cauley J, Guzick D. Premenopausal determinants of menopausal J, Guzick D. Premenopausal determinan

26 Davey Smith G, Shipley MJ, Rose G. Magnitude and cause of socio-economic differentials in mortality: further evidence from the Whitehall study. $\mathcal{f}$ Epidemiol Community Health 1990;44:265-70.

27 Marmot MG, McDowall ME. Mortality decline and widening social inequalities. Lancet 1986;ii:274-6.

28 Topo P, Klaukka T, Hemminki E, Uutela A. Use of hormone replacement therapy in 1976-89 by 45-64 year old Finnis women. F Epidemiol Community Health 1991;45:277-80.

29 Petitti DB, Wingerd J, Pellegrin F, Ramcharan S. Risk of vascular disease in women. Smoking, oral contraceptives, non contraceptive estrogens, and other factors. $7 A M A$ 1979;242:1150-4

30 Imperial Cancer Research Fund OXCHECK Study Group. Prevalence of risk factors for heart disease in OXCHECK trial: implications for screening in primary care. $B M \mathcal{F}$ 1991;302:1057-60. 